\title{
1. Introduction to the Handbook on Human Rights Impact Assessment: Principles, methods and approaches ${ }^{1}$
}

\author{
Nora Götzmann
}

\subsection{WHAT THIS HANDBOOK IS ABOUT}

This Handbook addresses the topic of human rights impact assessment (HRIA) in the context of business and human rights (BHR). With the endorsement of the United Nations Guiding Principles on Business and Human Rights (UNGPs) by the Human Rights Council in 2011, HRIA has become a key topic in this fast-developing field. Despite this, there are limited resources that comprehensively bring together theoretical and applied perspectives on the topic. This volume in the Handbook series contributes to addressing this gap and seeks to function as a key resource on HRIA for impact assessment practitioners, academics, businesses, investors, civil society, government actors and multilateral institutions alike.

Including diverse perspectives from 35 leading academics and practitioners from different world regions and institutional settings, the contributions in this Handbook provide a dynamic overview of current HRIA approaches and possible future directions. The key objectives of the volume are to:

- document current HRIA practice and critically reflect on this practice from different perspectives to identify strengths, weaknesses and ways forward;

- address gaps in theory and practice relating to core concepts such as effectiveness, accountability, measurement of impacts and the definition of 'good practice';

- consider how the rights, interests and needs of specific rights-holders, such as children, women and indigenous peoples, are accounted for;

- compare different HRIA approaches, including associated possibilities and limitations for addressing human rights impacts in diverse industry contexts (e.g., project-level assessment versus sector-level analysis, community-based approaches compared to company-commissioned assessments);

- present practical tools and insights to address shortcomings and maximize value added, such as those related to participation, capacity building and transparency;

- explore the functions of the different actors, standards and frameworks involved; and

- consider the role of HRIA in the context of broader regulatory and policy measures to ensure business respect for human rights and sustainable development.

The Handbook is structured in six parts:

I. Introduction: the topic of HRIA in the context of BHR is introduced and a summary of the different chapters of the volume presented (see Section 1.3, below). 
II. Methods and approaches: comprising an overview of the different HRIA approaches included in the volume, namely: company-commissioned assessments, community-based assessments, collaborative approaches, sector-wide approaches and assessments of trade agreements.

III. Rights-holders in focus: with chapters on children, women and indigenous peoples.

IV. Industry case studies: including contributions on the food and beverage, extractives, information and communication technologies (ICT), agricultural, travel and tourism, apparel, and infrastructure sectors.

V. Current challenges and future possibilities: with chapters on topics such as the meaningful participation of rights-holders; the relevance of local contextual factors - for example, conflict; the importance of multidisciplinary teams; measuring impacts and evaluating the effectiveness of HRIA; the role of different actors, standards and frameworks in fostering accountability; and the linkages between impact assessment and the 2030 Agenda for Sustainable Development (2030 Agenda) (United Nations General Assembly, 2015).

VI. Conclusion: capturing key reflections on the state-of-the-art of HRIA and possible future directions for theory and practice.

A note on scope is warranted. While HRIA is not exclusive to BHR, in this Handbook the focus is on HRIA specifically in the context of business projects and activities - such as mine sites, the supply chains of apparel factories, or trade agreements governing agriculture, to name but a few examples. Furthermore, collectively, the contributions in the Handbook are interested in HRIA in the context of all three pillars of the UNGPs: (1) the state duty to protect; (2) the corporate responsibility to respect; and (3) access to remedy (see Section 1.2, below). As such, this Handbook focuses not only on how to conduct HRIA for specific projects but also, critically, on the role of relevant regulatory and policy frameworks governing business respect for human rights. Relatedly, the roles of the state, businesses, financial actors, national human rights institutions, non-governmental organizations (NGOs), rights-holders, impact assessment practitioners and others in HRIA, are of key interest to the contributions in the Handbook.

\subsection{HUMAN RIGHTS IMPACT ASSESSMENT IN THE CONTEXT OF BUSINESS AND HUMAN RIGHTS}

\subsubsection{The Rationale for HRIA: The UNGPs and Human Rights Due Diligence}

It is evident that business projects and activities can have a wide range of impacts on human rights. With the endorsement of the UNGPs by the United Nations Human Rights Council (UNHRC) in 2011, it has been firmly established that businesses have a 'responsibility to respect' human rights. The UNGPs constitute a soft-law framework that addresses: (1) the state duty to protect against human rights abuses, including by third parties such as business enterprises; (2) the corporate responsibility to respect human rights, including through exercising human rights due diligence (HRDD); and (3) access for victims of business-related human rights abuses to effective judicial and non-judicial remedies (UNHRC, 2007, 2008, 2011a). HRDD is a process by which a business identifies, prevents, mitigates and accounts for how it addresses the adverse human rights impacts with which it is involved. The assessment of 
human rights impacts is a critical step in this process and HRIA has gained traction as one of the tools available to business enterprises, NGOs, governments and other stakeholders to assess the impacts of business activities on human rights.

In BHR, HRIA can be defined as a process for identifying, understanding, assessing and addressing the adverse effects of business projects and activities on the human rights enjoyment of impacted rights-holders such as workers and community members (Felner, 2013; Götzmann et al., 2016b). Depending on the type of HRIA approach (e.g., company-commissioned, community-based, trade agreement assessments) there will obviously be differences in the precise definition, objectives and actors involved; however, common principles and assessment phases can be identified (these are further elaborated in Sections 1.2.2 and 1.2.4, below). A key point is that HRIA seeks to provide detailed and evidence-based analysis that takes into account different perspectives and contributes to decision-making about business activities that may impact on people's enjoyment of their human rights. It can provide a structured approach through which to (see, e.g., Felner, 2013; Götzmann et al., 2016b; Walker, 2009):

- identify adverse human rights impacts, including understanding these from the perspectives of impacted rights-holders;

- contribute to effective HRDD by determining measures to address any adverse human rights impacts identified through prevention, mitigation and remediation;

- analyse the human rights implications of specific legal, regulatory and policy measures concerning business activities;

- facilitate meaningful dialogue between stakeholders in a given context, including business actors, rights-holders and other relevant parties (in particular, human rights actors);

- facilitate participation and learning of those stakeholders involved in the impact assessment, including through awareness-raising of respective rights, responsibilities and duties;

- enhance the accountability of state actors and businesses through documenting the impacts that have been identified and the actions proposed to address these, including by empowering rights-holders to hold state actors and businesses to account for adverse business-related human rights impacts; and

- build partnerships between the stakeholders involved to address human rights impacts, including through developing joint actions to address cumulative impacts or legacy issues.

HRIA involves several phases or steps. These may be broken down in varying ways or have different names but broadly include: screening, planning and scoping, data collection and baseline development, analysing impacts, impact mitigation and management, monitoring, reporting and evaluation (e.g., Abrahams \& Wyss, 2010; Felner, 2013; Götzmann et al., 2016b; Harrison, 2010; Walker, 2009). While it may be useful to divide the HRIA process into different phases for planning and implementation purposes, it is important to recognize that the assessment is an iterative process that should facilitate continuous learning and analysis throughout. A thorough assessment of human rights impacts is unlikely to be adequate, effective, or even feasible, if conducted purely as a desktop research exercise. Instead, HRIA must be a participatory process, requiring extensive background research, fieldwork and the participation of potentially affected rights-holders (e.g., workers, women and men in local communities, consumers) and other stakeholders (e.g., business, government and civil society actors). Engagement with rights-holders and other stakeholders as part of the process is essential and should be situated as the core cross-cutting component of any HRIA (e.g., Columbia Center on Sustainable Investment et al., 2017; Felner, 2013; González, 2014; Götzmann et al., 
2016b; Harrison, 2010, 2011; Rights \& Democracy [R\&D], 2011; Tamir \& Kearney, 2015; UNHRC, 2011a, 2011b; Walker, 2009).

\subsubsection{Origin and Original Elements: Environmental, Social, Strategic, Sustainability and Human Rights Impact Assessment}

HRIA draws on more established assessment methodologies, such as environmental impact assessment (EIA) ${ }^{2}$ and social impact assessment (SIA). ${ }^{3}$ However, while HRIA has a number of things in common with these more established practices, there are also some notable differences and a number of 'original' or 'essential' elements of HRIA can be identified. These aspects are briefly explored in this section to contextualize the different HRIA approaches included in the Handbook (outlined in Section 1.2.3, below).

EIA, and to a lesser but nevertheless significant degree, SIA, are now a standard part of due diligence in many business contexts - in particular, large-scale projects such as mines, oil and gas projects, dams and large infrastructure developments (Esteves et al., 2012; Morgan, 2012). Frequently, impacts are assessed using a combined environmental, social and health impact assessment (ESHIA). In many jurisdictions, EIA is required by law as part of a project approval process. In some cases, social dimensions are included within the definition of environmental impact. However, regulatory requirements for conducting SIA remain limited (Vanclay, 2014). Companies undertake EIA and SIA for a range of reasons, including regulatory and financing requirements, as part of complying with company standards, as well as to meet or respond to social expectations. As such, it is now generally acknowledged that EIA and SIA not only perform the role of ensuring regulatory approval but that they are key corporate risk and impact management tools (Esteves et al., 2012; Morgan, 2012).

Beyond the project level, impacts of business activities may also be assessed in the form of strategic environmental assessment (SEA) (e.g., Fundingsland Tetlow \& Hanusch, 2012) or through trade sustainability impact assessments (TSIAs) (e.g., Buergi Bonanomi, 2017; European Commission, 2015, 2016). These two types of assessment focus more on the overall legal, regulatory and policy frameworks governing business projects and activities. Such assessments may focus on specific industries, a particular geographic area, or a particular trade agreement.

Compared to more established practices such as EIA and SIA, the field of HRIA is relatively new. Within emerging practice, several strands of HRIA have been identified, including in the areas of development, the right to health, children's rights, business activities, international trade and investment, and impact assessments conducted for public authorities (e.g., Harrison \& Stephenson, 2010). It is worth noting that within and between these strands, the focus is diverse in terms of the rights-holders and duty-bearers involved, the level of detail in the methodologies and analysis, and the precise purpose and intent of the assessments (Felner, 2013; Harrison \& Stephenson, 2010). For example, in the case of HRIA conducted for government programmes, the focus might be on establishing whether a certain human-rights-focused intervention is meeting its objectives in terms of improving the realization of the particular human right(s) in question - such as an analysis of whether a government equal opportunities programme is effective in generating more employment opportunities for target groups such as women or ethnic minorities. In the BHR context, on the other hand, the focus to date has primarily been on identifying, usually through ex post assessments, the adverse impacts of business activities on human rights enjoyment (Felner, 2013; Harrison, 2010, 2011). 
The development of HRIA methodology and practice in BHR has been driven by different stakeholders with the view to enhancing accountability of business and state actors to avoid and address adverse human rights impacts associated with business activities. Civil society and international human rights actors, in particular, made instrumental earlier efforts. The Canadian organization Rights \& Democracy (2011), for instance, developed a methodology for community-based HRIA, putting rights-holders at the centre of assessments (see also Chapters 3, 4 and 11). From the UN, the UNGPs have been a key driving factor, as have the UN Guiding Principles on Human Rights Impact Assessments of Trade and Investment Agreements, developed by the UN Special Rapporteur on the Right to Food (UNHRC, 2011b; see also Chapters 6,13 and 25). The role of HRIA in the context of business activities has also been noted by several of the UN treaty bodies, as well as regional human rights actors such as the Inter-American Court of Human Rights (see Chapters 8, 23 and 26). For instance, the United Nations Committee on Economic, Social and Cultural Rights (ICESCR Committee) (2016) has recommended that the state strengthen 'legislation governing the conduct of corporations registered or domiciled in the State party in their activities abroad, including by requiring these corporations to conduct human rights impact assessments prior to making investment decisions' (para. 16). The ICESCR Committee (2017) has also recommended that states identify any potential conflict between their obligations under the International Covenant on Economic, Social and Cultural Rights (ICESCR) and under trade or investment treaties, suggesting that the "conclusion of such treaties should therefore be preceded by human rights impact assessments that take into account both the positive and negative human rights impacts of trade and investment treaties, including the contribution of such treaties to the realization of the right to development' (para. 13). However, business actors also made important contributions. In 2010, for instance, the International Business Leaders Forum, International Finance Corporation and UN Global Compact published a guide on HRIA (Abrahams \& Wyss, 2010). As elaborated in several chapters in this Handbook, more recently, and in large part in response to calls from civil society and human rights bodies, business actors, governments and financial institutions are increasingly addressing the topic of HRIA in BHR, including by developing guidance and setting requirements for assessment in corporate policy, lending requirements or government regulation (see, e.g., Chapters 2, 6, 22 and 25). While both states and businesses have a role to play regarding HRIA, it is important to note their differentiated and complementary responsibilities, as articulated clearly in the UNGPs.

The UNGPs set expectations for both state and business actors with regard to assessing and addressing the adverse impacts of business activities. With regard to state actors, for instance, Principle 8 emphasizes the need for policy coherence. This means, for example, that a state's laws, policies and objectives in the area of trade and investment should not be inconsistent or at odds with the state's international human rights law obligations (UNHRC, 2011a, 2011b). Similarly, Principle 3 notes that national laws, policies and regulations - including, for example, laws on investment, impact assessment and the environment - should be consistent with international human rights law (UNHRC, 2011a). Principle 4 is also of particular interest, dealing with the topic of the state-business nexus. Essentially, this principle recognizes that where a state has a particular interest or influence in business activities, a human rights abuse by the business actor(s) in question may entail a violation of the state's own human rights obligations. As such, heightened due diligence is expected where the state owns or substantially controls business activities - for example, state-owned enterprises, privatization of essential services, or financial institutions owned or backed by the state (UNHRC, 2011a). In summary, 
the state duty to protect requires the state to assess the human rights impacts of its own business activities, as well as consider its role in regulating the assessment of human rights impacts of private businesses and other relevant actors, such as financial institutions.

Businesses, in turn, are expected to respect human rights by using a process of 'due diligence', in which the assessment of human rights impacts is a critical step. It is important to appreciate that the UNGPs expect businesses to identify and assess their human rights impacts, not to conduct HRIA per se. Thus, while stand-alone HRIA (i.e., assessment that focuses explicitly on human rights) may be one approach taken, the UNGPs do not foresee this as the only approach, indicating that the assessment of human rights impacts may also be incorporated within other appropriate processes, as long as the focus on human rights is comprehensive (UNHRC, 2011a). It is important to acknowledge that businesses will need a suite of HRDD tools to ensure respect for human rights and that HRIA will not be the most appropriate methodology for all situations. For example, the extent to which HRIA can meaningfully address human rights impacts in all corners of complex supply and value chains, or in industries that are characterized by an extensive geographic reach, are key discussion points in the volume (see, e.g., Chapters 10, 12, 14 and 15). At the same time, to strengthen HRIA practice, it is important that what constitutes 'good practice' HRIA is further defined and distinguished from other due diligence tools - such as risk assessments, gap analyses or supply chain management - to ensure that HRIA methodologies developed and applied make a meaningful contribution to addressing adverse impacts. While a range of different due diligence tools are needed to respond to different needs and together make up a solid HRDD architecture, it is important to be clear about what does or does not constitute HRIA and what its particular value added is (this point is discussed further in Section 1.2.4, below and throughout the Handbook).

As noted above, while HRIA draws on more established assessment methodologies, a number of 'original' or 'essential' elements can be identified. Drawing on both scholarly literature and practical guidance on HRIA, these can be summarized as follows.

First, HRIA is based on internationally recognized human rights standards and principles, that is, these are used as the benchmark for the impact assessment and to guide the framing and process of the assessment (e.g., Abrahams \& Wyss, 2010; Felner, 2013; Götzmann, 2017; Götzmann et al., 2016b; Harrison, 2010, 2011; Norwegian Agency for Development Cooperation [NORAD], 2001; Salcito, 2015; UNHRC, 2011a, 2011b; Walker, 2009). Human rights are internationally agreed-upon standards and principles and, as such, establish an authoritative benchmark for impact assessment; other types of impact assessment tend to use a diverse array of standards as benchmarks and may not cover the civil and political, or economic, social and cultural rights comprehensively (e.g., Götzmann et al., 2016a, 2016b; Kemp \& Vanclay, 2013; Mungoven, 2016; Walker, 2009). Use of international human rights standards also includes drawing on authoritative interpretations, such as established jurisprudence or guidance developed by UN treaty bodies and special procedures, in the analysis of impacts (see especially Walker, 2009). It also involves being comprehensive by taking into account potential impacts on all rights, as well as recognizing the interdependence and interrelatedness of impacts, whereas other types of impact assessment may be narrower in their focus.

Second, in HRIA, participation of rights-holders, duty-bearers and other human rights stakeholders in the impact assessment is central (e.g., Columbia Center on Sustainable Investment et al., 2017; González, 2014; Götzmann, 2017; Götzmann et al., 2016b; Hamm \& Scheper, 2012; Harrison, 2010, 2011; Hill \& Newell, 2009; Hunt \& MacNaughton, 2006; Oxfam America \& R\&D, 2010; R\&D, 2007, 2011; Salcito, 2015; Tamir \& Kearney, 2015; 
UNHRC, 2011a, 2011b; Walker, 2009). In HRIA, meaningful participation in the impact assessment process can be as important as the outcomes (e.g., Watson et al., 2013), and rights-holders are considered to be active agents in the impact assessment process. While public participation is a standard component of impact assessment processes such as EIA and SIA, taking a human-rights-based approach (HRBA) places further emphasis on participation in terms of questioning and broadening the points in time at which participation occurs; the level of information sharing involved in participation and consultation activities; and empowerment and capacity building of individuals to participate in the impact assessment. The human rights framework also facilitates drawing on human rights institutions, networks and expertise in the impact assessment itself, as well as in the implementation of recommendations and mitigation measures (Felner, 2013; Walker, 2009).

Third, HRIA pays heightened attention to equality and non-discrimination (e.g., de Beco, 2009; González, 2014; Götzmann, 2017; Götzmann et al., 2016a, 2016b; Harrison \& Stephenson, 2010; R\&D, 2011; Salcito, 2015; UNHRC, 2011a, 2011b; Walker, 2009). International human rights place significant emphasis on non-discrimination and equality, and these terms are arguably more clearly defined than notions such as equity, which may be applied by other types of impact assessment. Furthermore, equality and non-discrimination in human rights provide parameters for the systematic analysis of impacts experienced by vulnerable individuals and groups, gender dynamics, and consideration of the differential distribution of adverse impacts (and benefits), through a clear focus on impact analysis at a disaggregate level (e.g., Felner, 2013). In addition, by applying the international human rights framework, the specific rights attributed to specific individuals (e.g., women, indigenous peoples, children, persons with disability) come to the fore, further strengthening the attention given to those who may be most vulnerable, marginalized or discriminated against (e.g., Hill \& Newell, 2009; see also Part III of this Handbook). As human rights inhere in the individual, HRIA limits offsetting, such as accepting impacts on certain individuals for the greater good or through positive contributions (e.g., Götzmann et al., 2016a). In short, use of the human rights framework demands and facilitates broadening and deepening the analysis in terms of equality and non-discrimination.

Fourth, HRIA places focus on accountability - including transparency, access to information and access to remedy (e.g., Felner, 2013; González, 2014; Götzmann et al., 2016b; Hamm \& Scheper, 2012; Harrison, 2010, 2011, 2013; MacNaughton, 2015; Massarani et al., 2007; Mungoven, 2016; Oxfam America \& R\&D, 2010; Salcito, 2015; Salcito \& Wielga, 2012; UNHRC, 2011a, 2011b; Walker, 2009). Transparency is imperative both throughout the impact assessment process, as well as with regard to the results. Considering transparency from the perspective of the right to access to information includes emphasis on a full range of parameters, such as the type of information being disclosed to rights-holders, the points in time, language and other accessibility factors. The human rights framework pays particular attention to accountability through the recognition of rights-holders as having entitlements for which respective duty-bearers have duties and responsibilities for upholding these rights (e.g., Felner, 2013; Götzmann, 2017; Walker, 2009). Arguably, this provides greater imperatives for the implementation of measures to address impacts than provided by impact assessment frameworks that are not based on human rights law standards. Relatedly, the emphasis of the human rights framework on access to remedy - both as a right in and of itself as well as a component of accountability - indicates the need for a stronger focus on this in HRIA than 
what may be required or expected in other types of impact assessment (e.g., Götzmann, 2017; Harrison, 2013; Kemp \& Vanclay, 2013; Watson et al., 2013; see also Chapter 23).

\subsubsection{Approaches to HRIA: Company-commissioned, Community-based, Collaborative, Sector-wide, and Trade Agreement Assessments}

This Handbook takes an inclusive definition of 'HRIA' to encompass a number of different approaches. 'Company-commissioned' assessments (see especially Chapters 2, 10, 12, 14-23 and 25) refer to those HRIAs that are carried out for business projects or activities as part of HRDD. Both 'stand-alone' (i.e., specifically addressing human rights) and 'integrated' (e.g., such as when integrating human rights into ESHIA) approaches are included within this definition. It should be noted that while we use the term 'company-commissioned' for the purposes of the Handbook, some of the assessments featured may be better described as 'facilitated self-assessment' (e.g., Chapter 12) or 'company led' (e.g., Chapter 14). As this is an emerging field, the precise methodology applied for HRIAs carried out as part of due diligence and the level of external involvement in such assessments varies. As pointed out by a number of contributors in the volume, this variance, and frequent shortcomings in terms of external involvement and engagement, pose challenges in terms of developing good practice. We therefore use the term 'company-commissioned' to emphasize that HRIAs carried out for the purposes of due diligence should evidence a requisite level of external involvement with the view to ensuring accountability, that is, be carried out by an independent third party, involve an external advisory committee, be subject to independent review and so forth.

'Community-based' assessments (see especially Chapters 3, 4 and 11) are assessments that are initiated and driven by NGOs or civil society organizations (CSOs) on behalf of (potentially) affected communities to evaluate the specific impacts of a business project or activity on human rights. These types of HRIAs are characterized by a high level of involvement of rights-holders in the assessment process, who in some instances may even lead and carry out the assessment.

A 'collaborative approach' (see especially Chapter 4, as well as Chapters 3, 9, 19, 22 and 26), although largely conceptual (rather than empirically tested) to date, can also be conceived. This approach envisages a participatory and multi-stakeholder process involving the community and company from start to finish, where these stakeholders collaborate to design and implement the impact assessment, potentially with the involvement of the government as a third party. While this approach has not yet been tried in practice, it may present an interesting future development that could have the potential to address some of the shortcomings and criticism of both company-commissioned and community-based approaches.

'Sector-wide' assessments (SWIAs) (see especially Chapters 5, 14 and 26) address a particular sector as a whole (e.g., oil and gas, tourism, palm oil), usually within one country. SWIAs present an innovative approach as they consider the legislative and regulatory framework, cumulative impacts, as well as project-level impacts; they also direct recommendations to a number of different stakeholders, including companies, government actors, civil society, lending institutions and development agencies.

HRIAs of trade agreements (see especially Chapters 6, 13 and 25) comprise the fifth category addressed - including both stand-alone and integrated approaches. Such assessments focus on the content and negotiation of a particular trade agreement, sometimes focusing even further on a particular human right (or set of rights) that may be impacted by the agreement. In 
particular, the right to health in the context of essential medicines and the right to food in the context of agriculture have been the subject of such assessments (see, e.g., Harrison \& Goller, 2008; Walker, 2011). The ultimate aim of these assessments is to contribute to ensuring that trade rules are shaped such that adverse human rights impacts are avoided and they instead support enabling environments for the realization of human rights. As such, similarly to SWIAs, HRIAs of trade agreements take a broader perspective that reaches beyond the project level to encompass sector governance and regulatory considerations.

Broadly speaking, all these approaches follow similar impact assessment steps, including: screening, planning and scoping, data collection and baseline development, analysing impacts, impact mitigation and management, monitoring, reporting and evaluation - with stakeholder engagement ideally occurring throughout the process. Similarly, all approaches can be ex ante (i.e., occurring before the establishment or implementation of the business project or activities) or ex post (i.e., occurring once the business project or activities have already commenced or have been completed). HRIA should be conducted as early as possible in the project lifecycle and repeated and re-evaluated at regular intervals (e.g., in the case of EIA and SIA, review every three to five years is considered to be good practice) or at critical points (e.g., project expansion, preparation for decommissioning and closure, where there are significant changes in social and political circumstances and so forth). Furthermore, in planning and undertaking HRIA, it is important to recognize that the complexity of the assessment should be appropriately scaled to the particular context (i.e., the community context, whether it is ex ante or ex post, whether there are pre-existing conflicts etc.) and to the nature of the business project or activities (i.e., the size of the operation, the stage of operations, the specific location etc.). This also applies to consideration of how much time will be needed.

\subsection{4 'Good Practice' HRIA: Criteria for HRIA Content and Process}

To ensure that human rights are addressed comprehensively, it is important that the content, process and outcomes of the assessment apply and are compatible with international human rights standards and principles. Currently, however, the emerging practice of HRIA in BHR is very varied, which poses challenges for identifying and distinguishing good practice from weaker assessments, as well as clarity in terms of how HRIA is defined as compared to other types of HRDD tools and governance processes that seek to ensure business respect for human rights. For example, in terms of the focus, stakeholders involved and depth of analysis, current practice appears to include within the category of 'HRIA' anything ranging from a short desktop review to multi-month investigative processes involving numerous stakeholders and topics of analysis (cf., e.g., Bansal \& Wyss, 2013; Braunschweig et al., 2014; BSR, 2016; FIDH et al., 2016; Götzmann \& Bainton, 2019; Hamm et al., 2013; Kuoni Travel Holding, 2014; Kuoni Travel Holding et al., 2012; LKL International Consulting, 2014; Triponel Consulting, 2017; Wachenfeld et al., 2017; Wielga et al., 2009). At the same time, assessments and analysis with a different label (such as 'human rights assessment' or 'risk assessment') are frequently presented by companies or referred to by other stakeholders as HRIAs (cf., e.g., Arla, 2015; Hoffmann et al., 2018; On Common Ground Consultants, 2010; United Nations Economic Commission for Africa \& Friedrich Ebert Stiftung, 2017; Vattenfall, 2017). Notably, some of the assessments not explicitly labelled as 'HRIA' arguably contain more thorough analysis than some of those labelled as such. Again, the point is not to devalue the variety of HRDD that is needed to ensure respect for human rights but rather, the point is that 
this amorphousness in defining good practice HRIA can be problematic from the perspective of impact assessment practitioners, rights-holders, businesses, state actors and others. As suggested by Harrison (2013), without the development of 'shared normative understandings of what the HRIA process should represent, there is a danger that the nomenclature will lose its status as representing a robust evidence-based process of assessing impacts' (p. 115). By documenting, exploring and critically analysing current approaches, this Handbook attempts to make a contribution to further dialogue and debate about the role of HRIA in BHR, including better understanding what 'good practice' can and should entail and how it relates to other due diligence and governance processes that seek to ensure business respect for human rights. Understanding the core content and process elements that should constitute HRIA is an essential part of this process.

The UNGPs provide some basic recommendations for assessing human rights impacts: draw on internal and/or independent human rights expertise; undertake meaningful consultation with potentially affected rights-holders and other relevant parties; be gender-sensitive and pay particular attention to any human rights impacts on individuals from groups that may be at heightened risk of vulnerability or marginalization; assess impacts from the perspective of risk to people rather than risk to business; and repeat risk and impact identification and assessment at regular intervals (UNHRC, 2011a). However, they do not provide an elaborated methodology for doing so. Arguably, this is only logical given that the UNGPs provide a framework for BHR, rather than a detailed methodological approach. However, it also indicates a need for the further elaboration of what precisely the methodologies and practices for assessing human rights impacts should entail.

Despite the diversity, and at times divergence, in current HRIA approaches, it is possible to deduce several recurring elements in the literature and guidance. In addition to the UNGPs, literature and guidance of particular relevance include: sources articulating the 'original' or 'essential' elements of HRIA (e.g., Felner, 2013; Harrison, 2010, 2013; Walker, 2009); literature on the HRBA (e.g., Cornwall \& Nyamu-Musembi, 2004; International Human Rights Network [IHRN] et al., 2008; Nyamu-Musembi \& Cornwall, 2004; Office of the United Nations High Commissioner for Human Rights [OHCHR], 2006); sources that outline the stages or steps of HRIA in the form of practical 'how to' guidance, or by summarizing such available guidance (e.g., Abrahams \& Wyss, 2010; Danish Institute for Human Rights \& IPIECA, 2013; Götzmann et al., 2016b; Harrison \& Stephenson, 2010; Hill \& Newell, 2009; Lenzen \& d'Engelbronner, 2009; Natour \& Davis Pluess, 2013; NORAD, 2001; R\&D, 2011; Salcito \& Wielga, 2012); actual examples of HRIAs and the scholarly literature reflecting on such assessments (e.g., Bansal \& Wyss, 2013; Boele \& Crispin, 2013; Hamm et al., 2013; Kemp \& Vanclay, 2013; Kuoni Travel Holding, 2014; LKL International Consulting, 2014; Myanmar Centre for Responsible Business et al., 2014, 2015a, 2015b, 2018; Salcito, 2015; Watson et al., 2013; Wielga et al., 2009).

These recurring elements contain important references to the principles of the HRBA. Although the HRBA was developed in the field of international development cooperation (see OHCHR, 2006), the importance of adopting a HRBA in the context of HRIA has been emphasized (see, e.g., Felner, 2013; Harrison, 2010; Lenzen \& d'Engelbronner, 2009; for references in the context of SIA see also MacNaughton \& Hunt, 2011). According to the United Nations Stamford Common Understanding, the HRBA rests on three core components: (1) application of international human rights standards; (2) adherence to human rights principles, including using these to guide processes - for example, equality and non-discrimination, participation 
and inclusion, accountability and the rule of law; and (3) emphasis on accountability, including through the analysis of the roles and capacities of rights-holders and duty-bearers (OHCHR, 2006). Essentially, a HRBA stresses that both process and outcomes of interventions should be compatible with international human rights standards and principles, including by recognizing individuals as agents in their own development, rather than as mere 'subjects' or 'beneficiaries' of an intervention or programme (IHRN et al., 2008; OHCHR, 2006).

Drawing on these sources, it is possible to identify a number of recurring aspects, related to both content and process, which can be considered essential for HRIA to ensure consistency with international human rights standards and principles, and the expectations set out in the UNGPs. Drawing on current literature and guidance, Götzmann et al. (2016b) brought these elements together in a set of 10 criteria: five focusing on content and five focusing on process (Table 1.1). As demonstrated by some chapters in this Handbook, these criteria can be used to analyse and evaluate a particular assessment or approach, or to guide the development of HRIA methodology and practice (see, e.g., Chapters 11, 12 and 14). Based on such application, the criteria themselves should be subject to future evaluation and amendment to address any gaps or shortcomings identified.

\subsubsection{Challenges in HRIA Methodologies and Practice: Effectiveness, Participation, Accountability and Local Context}

HRIA is an emergent practice. As such, there are a number of key challenges that need to be considered. Several of these are addressed in different chapters of this Handbook. For introductory purposes, four are arguably worth noting in particular. These centre around: (1) outcomes and effectiveness; (2) the role of participation, capacity building and learning; (3) how to understand and enable accountability; and (4) the role of contextual factors, such as the presence of conflict or navigating between local culture and international norms.

To date, the outcomes and effectiveness of HRIA are insufficiently analysed (see, e.g., Chapters 15, 21, 22 and 25). If the 'value added' of HRIA is to be demonstrated, HRIA methodologies and practice need to be carefully evaluated to establish when, where and how assessments make a meaningful contribution to establishing business respect for human rights and where not. In much of the scholarly literature and practical guidance on HRIA to date, there is an implicit assumption that HRIA will contribute positively to the human rights enjoyment of workers, community members and other rights-holders adversely impacted by business activities. While this is certainly a core aim of HRIA, whether this is in fact the case needs to be investigated through empirical research and evidence, including conceptual refinement of how the effectiveness of HRIA is to be measured. Transparency of methodologies and assessments is a critical precondition for this to occur and must therefore be a key focus going forward. Likewise, further clarity around when HRIA is recommendable as compared to other types of due diligence processes should be further considered. As suggested in several contributions in this Handbook, there are tentative indications that HRIA does have something to add (e.g., as compared to audits, ESHIAs or sustainability assessments; see, e.g., Chapters 6, 10, 13, 15 and 19). However, consensus on what constitutes 'good practice' is still lacking, as is empirical evidence of the results of such good practice.

A second key area emerging in HRIA is around the role of participation, learning and capacity building of the different stakeholders involved (see, e.g., Chapters 2-6, 17 and 19). As outlined above, meaningful participation is a key human rights principle; rights-holders are 


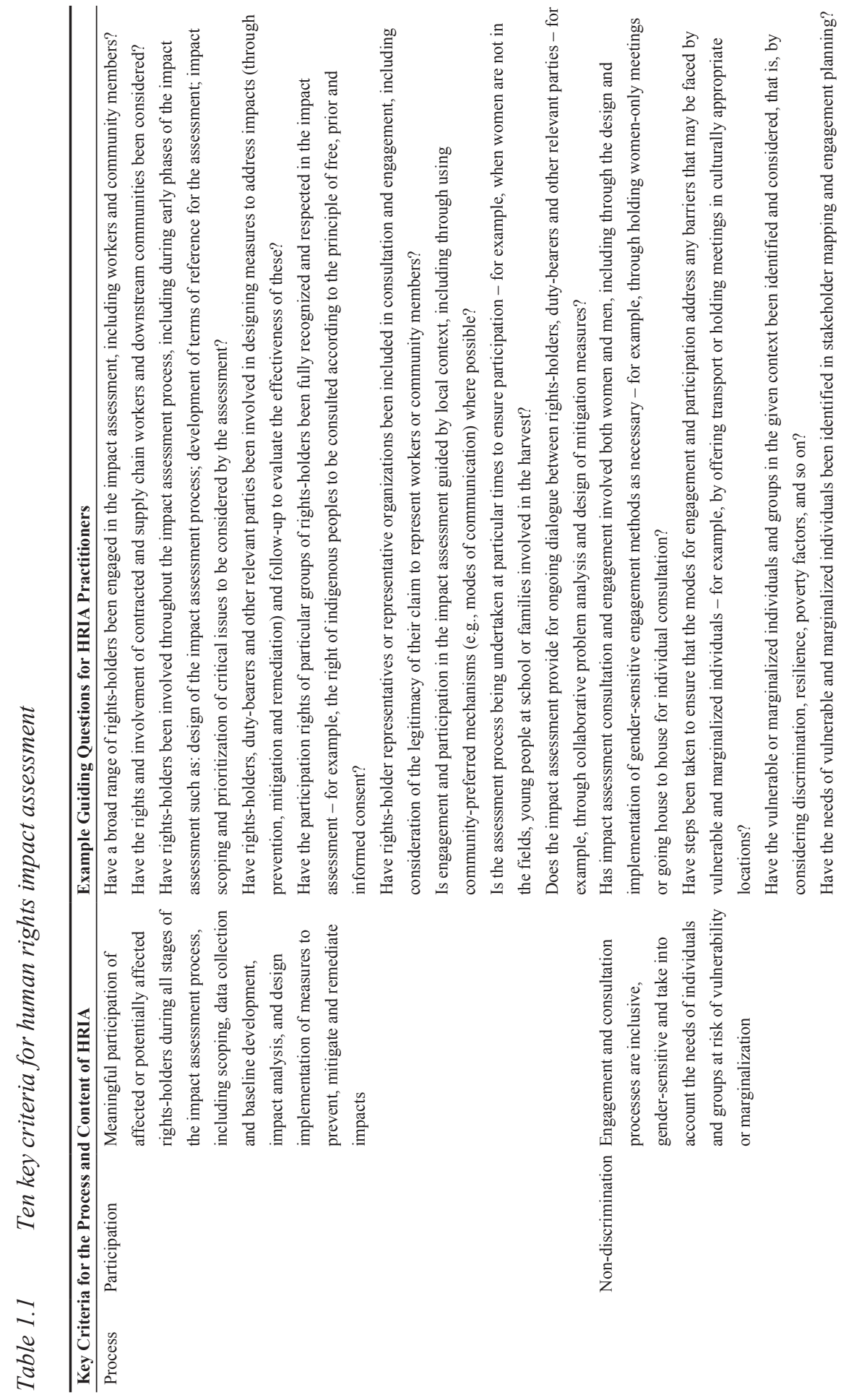




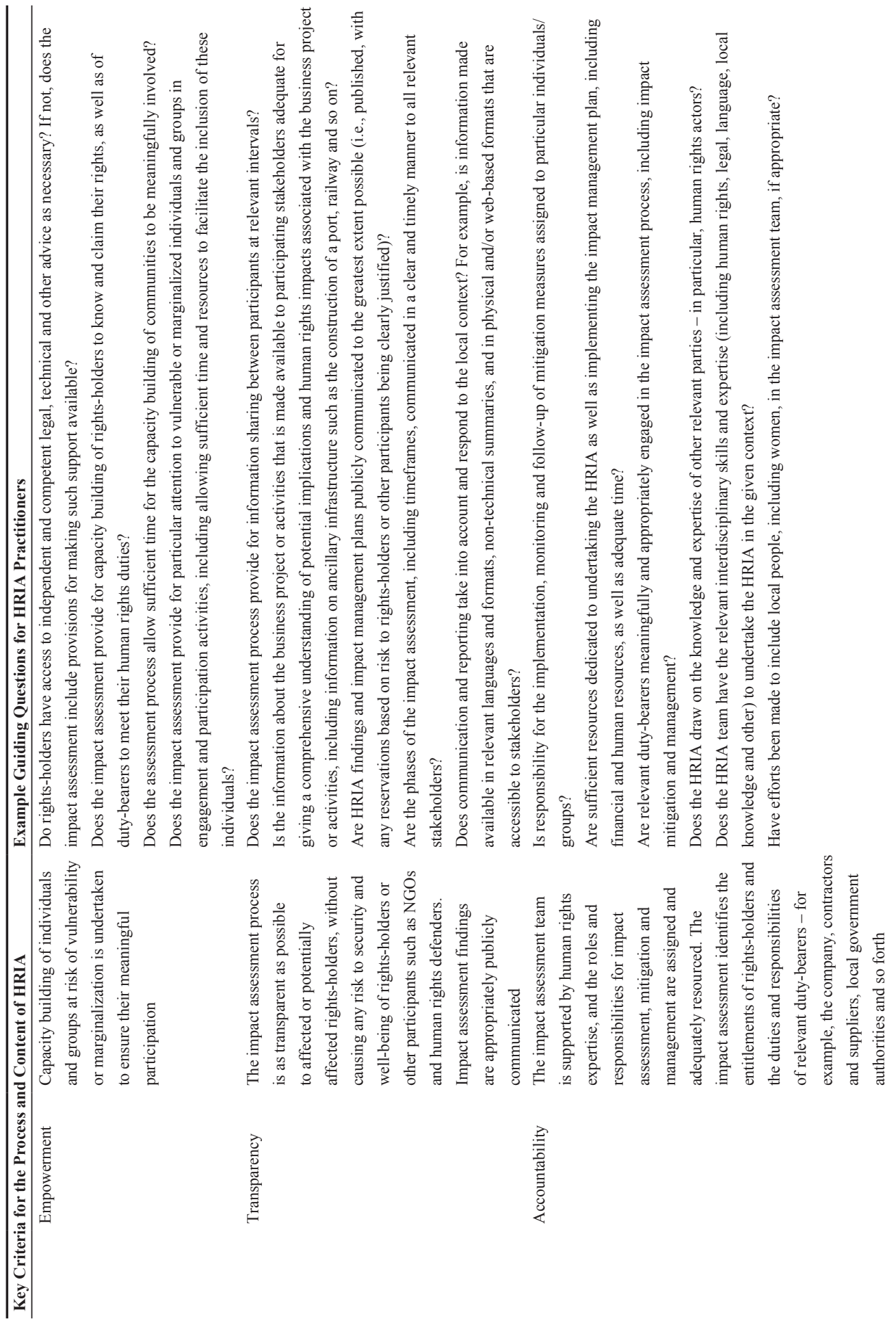




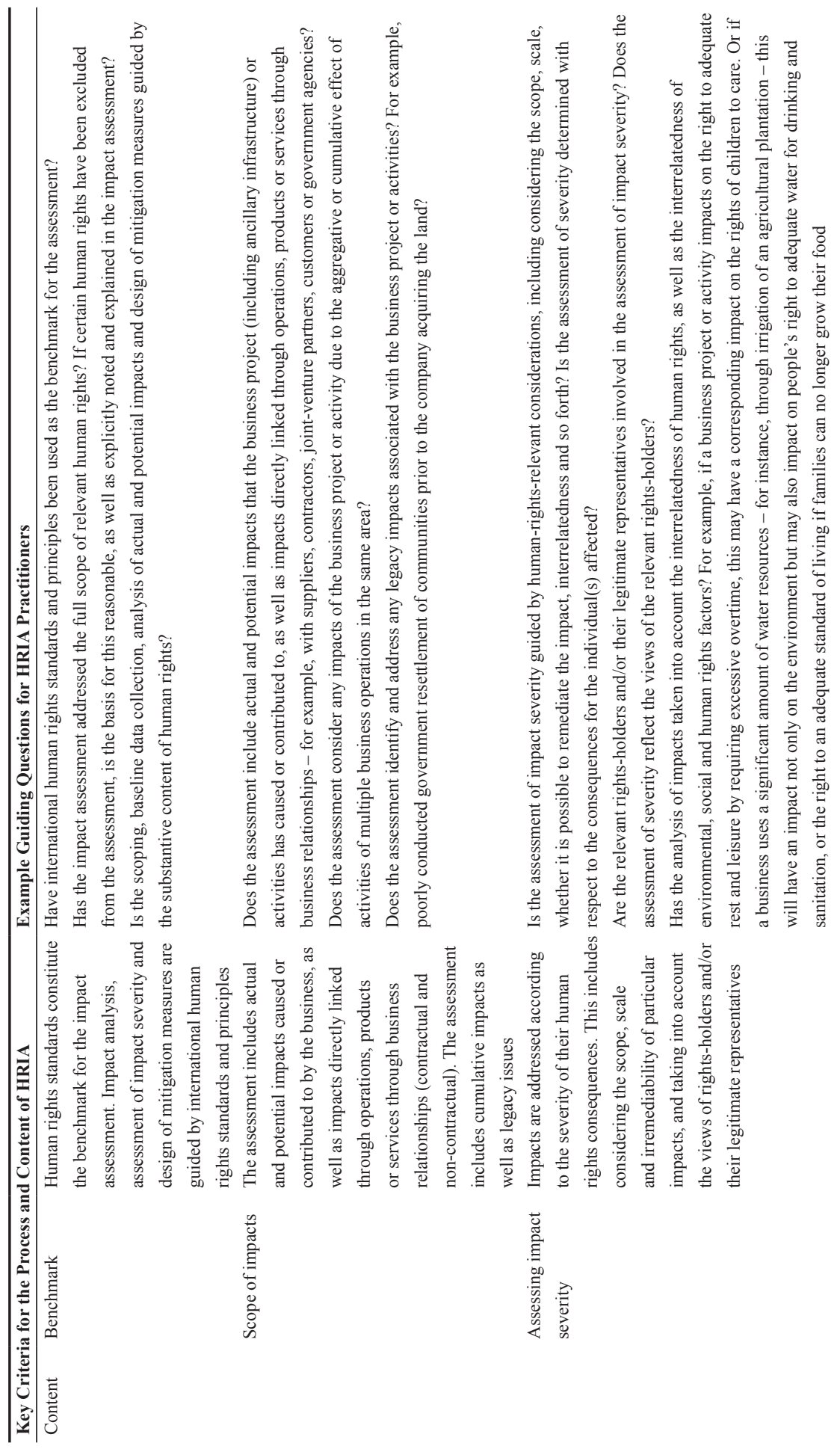




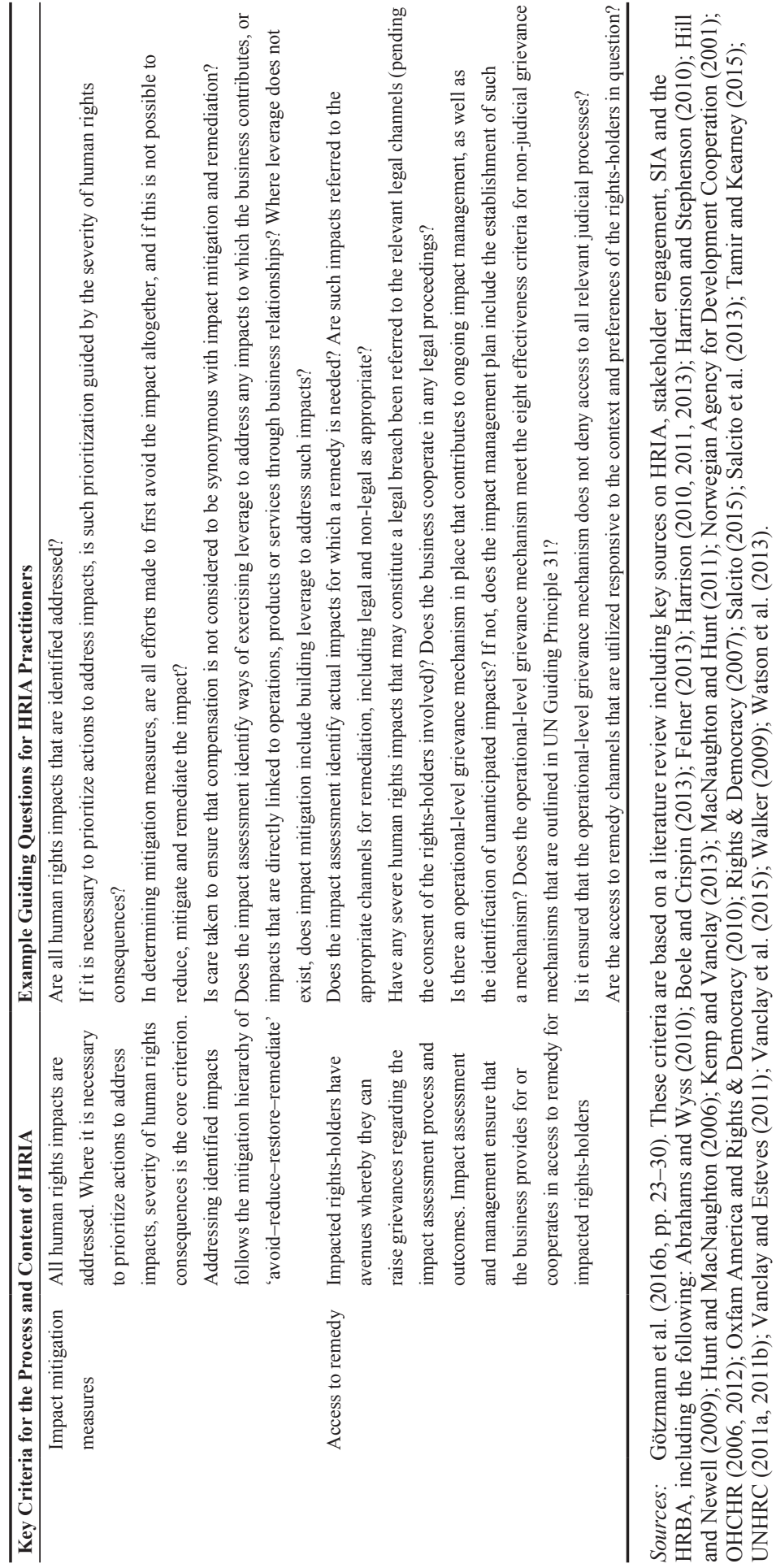


entitled to participate in decision-making that affects them; and the more severe the actual or potential impacts, the greater the imperative for the application of the principle of free, prior and informed consent (FPIC). As recognized in international human rights law, participation rights of indigenous peoples warrant particular attention due to the special connection of indigenous peoples to their lands, territories and resources, and by virtue of their right to self-determination (see Chapters 8 and 26). This strong focus on participation is a critical part of all the HRIA approaches captured in this Handbook. However, as also discussed, many aspects of understanding and implementing meaningful participation in HRIA could benefit from further attention. To what extent company-commissioned assessments can genuinely facilitate meaningful participation of rights-holders, for instance, remains questionable in the absence of greater attention to the requirements for capacity building, independent advice and accountability structures to guide dialogue between the different stakeholders involved in such assessments (see especially Chapters 2 and 17; for similar points in the context of HRIA of trade agreements see Chapters 6,13 and 25). However, not only the participation of rights-holders is at stake. Scholars and practitioners have pointed out, for example, that the participation and capacity building within companies that may be facilitated by the HRIA process can be invaluable for generating human rights capacity. Additionally, HRIA can help to foster implementation of effective due diligence across different business unit functions - in particular, where the HRIA process involves strong cross-functional collaboration (see, e.g., Chapters 10, 14 and 19). As such, some have argued that internal company learning through HRIA should be considered one of the core objectives of HRIA (e.g., Bakker et al., 2009; Boele \& Crispin, 2013; Kemp \& Vanclay, 2013). However, as noted by several authors in this volume, a precondition for such learning to occur is a requisite level of openness within companies, and, where company (or industry) culture remains averse to human rights, the effectiveness of HRIA is likely to be limited (see especially Chapters 2, 17 and 25). Furthermore, even where companies have policies and structures for collaboration and learning in place, this may not always translate into effective implementation in practice. Last, although the involvement of human rights actors is flagged as a key original element of HRIA (Walker, 2009), current practice does not seem to make as much use of this as would be desirable (e.g., through stronger involvement of key human rights actors such as national human rights institutions, UN special procedures or regional human rights actors).

A third central topic is around accountability. As outlined, accountability is not a one-dimensional concept and how it is defined in the context of HRIA warrants further elaboration (see especially Chapter 22). In particular, important elements such as transparency and enforceability need attention (see, e.g., Chapters 2 and 25) but also how HRIA relates to access to effective remedy (see Chapter 23). A key point on this topic relates to the roles and responsibilities of different actors. To date, much of the focus on HRIA in BHR has been on site-level impact assessments and the roles of companies, rights-holders and impact assessment practitioners in these; far less attention has been paid to the role of governments in setting requirements of businesses - for example, through laws, policies, regulations, guidance or education. The role of due diligence and performance standards of international financial institutions (IFIs) should also be considered (see, e.g., Chapter 24), as well as those of industry standards. Thinking through how to utilize or generate other accountability structures ranging from potential mechanisms such as UN reporting structures, independent monitoring bodies (e.g., Harrison, 2013) to site-level advisory and review committees (e.g., On Common Ground Consultants, 2010) - has been isolated and, as suggested in several chapters in this 
volume, the role of such structures could be explored much more widely going forward (see, e.g., Chapters 4, 5, 14, 15, 22 and 25). How HRIA relates to the 2030 Agenda and how these linkages could be utilized to strengthen accountability also remains under-explored (see Chapter 26), including when considering the use of particular instruments such as publicprivate partnerships (PPPs) that could be leveraged to enhance accountability (see Chapter 16). A key theme here also, is what purpose specific HRIAs can serve to drive accountability, as compared to wider policy and governance approaches that demand business respect for human rights by shaping laws, regulations and policies at national and multilateral levels to ensure that they are conducive to human rights protection. As pointed out by a number of authors in this volume, such considerations also require looking beyond the 'technical' aspects of HRIA to consider their 'political' nature (e.g., Chapters 12, 13, 15, 22 and 25).

A fourth core theme centres on the role of contextual factors and analysis. While it is acknowledged that context analysis is a key component of HRIA (as for any type of impact assessment), consideration of specific factors - be they to do with the geographic location, specific industry risks or other - arguably need to be better embedded in HRIA practice going forward. As demonstrated in the chapters in Part IV, the differences between industries are significant and if HRIA is to be effective, methodologies will need to be able to address and respond to these specificities. Likewise, the need for 'heightened' due diligence in conflict-affected or high-risk areas is generally accepted; however, what precisely this means remains under-explained (see Chapter 18). A further challenge in many contexts is posed by the need to navigate between international norms and local culture (see, e.g., Chapter 9). International human rights are universal entitlements and as such globally applicable. However, in practice, human rights are understood, conceptualized and realized in different ways in different contexts and cultures. Similarly, the notion that all human rights are interdependent and indivisible may not always fall easily into place in practice, as capacity and resource constraints of different actors as well as local context realities necessitate prioritization in specific settings. Such complexities are not always straightforward in practice and may require HRIA practitioners to confront their own assumptions and values, as well as challenge local norms in a culturally sensitive manner.

The chapters in this volume elaborate, discuss and challenge these four themes, as well as many others. The conclusion also returns to these discussion points (see Chapter 27). The following final section of this introduction provides a more detailed overview of the different parts and chapters in the Handbook.

\subsection{OVERVIEW OF THE HANDBOOK}

\subsubsection{Part II: Methods and Approaches}

This part of the Handbook provides an overview of current HRIA methods and approaches in BHR, including: company-commissioned assessments, community-based assessments, collaborative approaches, sector-wide approaches and assessments of trade agreements.

In Chapter 2, on company-commissioned assessments, Kendyl Salcito argues that through such assessments companies can create real opportunities for advancing the BHR agenda, predominantly by knowing their impacts and designing interventions to avoid, mitigate or remediate harms. Companies are responsible for conducting due diligence to ensure their 
operations respect human rights. Some take on this task by carrying out HRIAs for some or all their operations and activities. However, company-commissioned assessments have suffered from various shortcomings in methodological consistency and rigour, implementation and follow-up, which jeopardize their effectiveness. The chapter examines the processes, limitations and opportunities for improvement in the field of company-commissioned HRIA.

In Chapter 3, Caroline Brodeur, Irit Tamir and Sarah Zoen discuss the theory and practice of community-based human rights impact assessments (COBHRAs). They note that while HRIAs sit at the heart of businesses' due diligence obligations, workers and communities affected by large-scale business operations often lack the information, capacity and technical expertise to engage meaningfully with companies and governments in the assessment of human rights impacts. To overcome these shortcomings, communities may conduct their own COBHRAs. The chapter provides an overview of the COBHRA methodology and its application in two concrete case studies. The chapter also discusses key challenges and opportunities for the methodology. It is argued that by putting local communities at the forefront of the impact assessment, COBHRAs not only help to identify long-lasting solutions to human rights issues but also contribute to rebalancing power between stakeholders.

Taking their point of departure in some of the weaknesses that have been identified regarding company-commissioned and community-based approaches, in Chapter 4, Kaitlin Y. Cordes, Sam Szoke-Burke and Tulika Bansal explore a yet-untested approach for collaborative HRIA - defined as a joint process undertaken by project-affected people and a company, potentially with the host government or other stakeholders. The approach emphasizes deep collaboration between stakeholders. This differs from company-commissioned HRIAs, which usually do not create space for project-affected people to jointly define and implement the process. The chapter explores why stakeholders might wish to undertake a collaborative HRIA, as well as factors affecting the appropriateness of the approach in specific contexts. It also provides an overview of the collaborative approach to HRIA, including discussion of participants, key steps, structure and governance, methodology, dispute resolution and funding. Finally, the authors reflect on key challenges and opportunities relating to the local context, characteristics of the project and the people affected, and issues related to time and timing.

Following these three first chapters that focus more on project- or site-level assessments, in Chapter 5, Margaret Wachenfeld, Elin Wrzoncki and Luis F. de Angulo examine the methodology and practice of SWIA, a methodology developed to consider sector, cumulative and project-level human rights impacts holistically. The chapter starts with outlining the methodology and discussing the rationale for undertaking SWIA as compared to other types of methodologies used to identify, analyse and address impacts of business activities on human rights. The process of conducting SWIA is then described, drawing on practical examples from Myanmar and Colombia. The authors argue that SWIA can help to create a shared vision of responsible business conduct across stakeholders through facts-based analysis and dialogue. This shared vision can in turn provide the basis for actions by different stakeholders to address the adverse human rights impacts of a sector comprehensively. The chapter concludes with a discussion of challenges, lessons learned and pathways forward for the future development and application of this methodology.

In Chapter 6, Simon Walker addresses the methodology and current practice of trade agreement HRIAs, setting out the process steps for such assessments and identifying the actors, time and resources involved. The assessments covered include HRIAs that focus specifically on human rights (stand-alone HRIAs) and assessments that integrate human rights alongside 
the analysis of economic, environmental and social impacts (integrated IAs). The chapter examines opportunities and challenges related to HRIA of trade agreements, highlighting the broader context of HRDD of business projects and activities under the UNGPs, which has provided both guidance and impetus for HRIA of trade agreements. The chapter highlights the incorporation of participatory assessment techniques as a particular challenge facing trade agreement HRIAs and encourages development of further methodological guidance in this regard.

\subsubsection{Part III: Rights-holders in Focus}

Given the core focus of international human rights law on non-discrimination and equality, Part III of the Handbook focuses on three particular groups of rights-holders: children, indigenous peoples and women. Non-discrimination is recognized across human rights treaties and many of the core human rights conventions focus on particular rights-holder groups. This reflects the recognition that these rights-holders are frequently subject to marginalization and discrimination, and that this can give rise to vulnerability. For example: due to their physical and mental state of development, children are particularly susceptible to developmental damage from exposure to chemicals or emotional abuse, which impacts them differently than it would grown adults; indigenous peoples frequently have special relationships to lands, territories and resources and may therefore be particularly adversely impacted by business activities that impact on these resources (e.g., large-scale industries); and women's reproductive role gives rise to the need for specific protections in the area of maternal and reproductive health. In a business context, such factors mean that certain rights-holders will be impacted differently by business activities and bear a disproportionate burden of adverse impacts and benefits. For HRIA to effectively address this, attention therefore needs to be paid both to the particular rights enjoyed by specific rights-holders, as well as the differential experience of impacts in a given context. International human rights law recognizes substantive and not only formal equality (see Chapter 9). This means that the use of temporary 'special measures', for instance, is considered to be an acceptable, and indeed necessary, part of ensuring non-discrimination. Despite this, many business-oriented frameworks continue to struggle to implement this understanding of equality. Importantly, the chapters in this part also recognize intersectionality (Crenshaw, 1991; see also Chapter 9); that is, that groups of rights-holders, such as women, are not homogeneous and that some individuals may experience multiple sources of discrimination. As argued by Crenshaw (1991), this is not as simple as a person experiencing 'double' discrimination, but instead multiple identity factors give rise to a specific position and experience of discrimination that warrants attention particular to that experience.

Beginning Part III with a chapter on children and youth, Tara M. Collins argues in Chapter 7 that, despite their relevance to the BHR discourse, children and youth and their human rights in relation to business activities are inadequately considered. Hence, the chapter has several objectives: (1) improve awareness of children's rights among stakeholders working with HRIA; (2) discuss key challenges and opportunities for respectful inclusion of children and youth in HRIA of business projects and activities; and (3) support development of more comprehensive impact assessments through inclusion of children's rights. While there are some demands involved with the inclusion of children's rights in HRIA, it is argued that this does not excuse lack of attention to this population group. Greater efforts can facilitate understanding and practice of reflecting child rights in HRIA. Indeed, it is essential to mainstream 
them in order to respect young people's human rights as well as ascertain the significance of business activities upon them.

In Chapter 8, Cathal Doyle considers the relationship between HRIA and FPIC in the context of indigenous peoples' rights. Indigenous peoples are recognized under international human rights law (IHRL) as a distinct category of rights-holders with sui generis collective rights. To guarantee these rights in the context of business activities, IHRL has established several state duties and associated business responsibilities. These include the requirements to conduct HRIA to assess potential impacts of business activities on indigenous peoples' rights, and to consult with them in good faith in order to obtain FPIC to those impacts. The chapter examines the prospects for the operationalization of a mutually reinforcing relationship between indigenous-rights-based conceptions of FPIC and HRIA, in which HRIAs inform FPIC processes, and FPIC processes legitimize, shape and give effect to HRIAs. It probes the implications FPIC has for the scope, timing, process and content of HRIA and associated challenges and opportunities, including the potential of HRIA to further the realization of FPIC.

In Chapter 9, Bonita Meyersfeld addresses the rights of women and girls in the context of HRIA and argues for the importance of gendered impact assessments. Gender-based discrimination places certain people in certain roles from the moment of birth. Women are often ascribed particular characteristics or capabilities that will in turn determine their role and work in a specific context. The result is that men and women are funnelled into a life path that takes them further away from their inherent, individual capabilities and closer to the role assigned to them because of their sex. This role allocation is often normalized and invisible. This is a problem for HRIA. Those who assess the impacts of business projects and activities may not be able to identify the layers of harm that could occur for women in an affected community. The chapter demonstrates how gender-based discrimination often is not part of the impact assessments carried out for business projects, leading to consequences that, although avoidable, cause unforeseen and devastating consequences for women in affected communities.

\subsubsection{Part IV: Industry Case Studies}

This part of the Handbook explores several industry case studies, including: experiences with company-commissioned HRIAs in the food and beverage sector; a community-based assessment of a mining exploration project in Mexico; possible approaches to HRIA in the ICT sector; the role of HRIA of trade agreements affecting the agricultural sector; a comparative analysis of different HRIA approaches in the travel and tourism sector; analysis of the function of HRIA in the global supply and value chains of the apparel sector, including how HRIAs differ from audits; and an examination of the potential utility of HRIA in PPPs governing large-scale infrastructure projects. Each of the chapters illustrates some of the human rights challenges that may be particular to a certain sector, as well as reflecting on what this may mean for the application and development of HRIA methodology for different industry sectors. The chapters also provide further insights into how the different HRIA approaches introduced in Part II function in practice.

In Chapter 10, Yann Wyss and Tulika Bansal discuss how HRIAs have been a centrepiece of Nestlé's overall HRDD, helping the company to know and show that it respects human rights both at the corporate and operations levels. The chapter is based on the ten-year collaboration between Nestlé and the Danish Institute for Human Rights in developing HRIA methodology and conducting over a dozen HRIAs in Nestlé's operations and its supply chains. First, 
the authors describe the applied HRIA methodology and how it has evolved and improved over the years. Through three case studies, distinct features of HRIA are provided and key implementation challenges discussed. The chapter concludes with a potential way forward for HRIAs for Nestlé, which could be applicable for the food and beverage sector more widely, or for other companies with complex supply chains.

In Chapter 11, Alejandro González Cavazos analyses the implementation process of an ex ante COBHRA carried out in Mexico regarding a proposed gold-silver mine. The HRIA was conducted by a grassroots organization of community members affected by the mining exploration, accompanied by three CSOs. The chapter identifies good practices and areas of improvement for future assessments. It analyses whether the HRIA followed a HRBA and fulfilled the essential elements of good practice. The analysis highlights community participation and empowerment during the process - in particular, noting the usefulness of innovative participatory approaches such as power mapping and collective social mapping. The chapter concludes by identifying improvement areas and giving recommendations to address them.

In Chapter 12, Rikke Frank Jørgensen, Cathrine Bloch Veiberg and Niels ten Oever explore the role of HRIA in the ICT sector, present a concrete case study, and discuss some of the lessons learned from practice. The diverse nature of the ICT sector and the distributed architecture of the internet results in the various ways in which the business activities of the sector intersect with human rights. The chapter provides an overview of how human rights are relevant to the sector, including examples of adverse human rights impacts and of different types of human rights analyses performed in the sector. It then considers a concrete HRIA case study, targeting a top-level country code domain name registry in the Netherlands. The final part of the chapter draws on the case study to highlight and discuss some of the key issues and challenges for conducting HRIA in relation to domain name providers.

In Chapter 13, Elisabeth Buergi Bonanomi and Irene Musselli address the topic of HRIA in the context of trade agreements and agriculture. The authors note that without context-specific trade rules, North-South trade can worsen people's livelihoods. HRIA can ensure that trade rules are shaped to support enabling environments for human rights realization. Important benchmarks include access to adequate food and maintenance of equitable working conditions; food-system diversity is also particularly relevant for shaping human-rights-conducive trade options. The chapter discusses how stakeholders can draw inspiration from existing sustainable agricultural trade theory and from empirical experience, as illustrated by the example of palm oil and the planned European Free Trade Association-Malaysia Free Trade Agreement. The authors elaborate on the growing momentum towards acknowledging trade measures relating to processes and production methods (PPMs). In conclusion, they consider whether a more pragmatic, deliberation-based approach to trade negotiations and the strengthening of the rule of law in external affairs could yield even better results than specific HRIAs.

In Chapter 14, Sibylle Baumgartner and Tulika Bansal provide an overview of two distinct types of HRIA conducted in the travel and tourism industry: a company-commissioned assessment from India and a SWIA from Myanmar. The chapter compares the different methodologies applied against 'good practice' criteria for HRIA and discusses challenges encountered in each. Based on this comparative analysis, recommendations for future assessments are suggested. The chapter also evaluates the opportunities that HRIA creates, demonstrating that it is a learning process for the travel and tourism industry and that there is no singular way to assess human rights impacts. Furthermore, the authors note that collaboration within the industry is crucial for achieving effective identification and implementation of mitigation measures that 
meaningfully address adverse human rights impacts. The chapter concludes with a number of outstanding challenges and recommendations for HRIA in the travel and tourism industry, and possibly beyond.

In Chapter 15, Christian Scheper addresses the challenge of conducting HRIA in the context of transnational value chains, with a focus on the apparel industry. The chapter identifies two main challenges for creating meaningful HRIA approaches: (1) a managerial challenge in light of major conflicts of interest in buyer-driven value chains; and (2) an epistemic challenge based on the domination of corporate-led forms of knowledge generated through supply chain assessment techniques. The chapter suggests a conceptual turn in the debate about criteria for HRIA in buyer-driven value chains, which takes seriously the political character of HRIA and separates it from established practices of company-led value chain assessments (based on audits, certification and benchmarking). Instead, Scheper proposes a political conception of HRIA that focuses on institutional capacities for workers to address power asymmetries in the value chain and make claims based on national labour laws and international human rights.

Concluding Part IV of the Handbook, in Chapter 16 Josua Loots considers the potential of HRIA in the context of PPPs for essential services infrastructure projects, with a specific focus on Africa. PPPs are often used as a procurement method and project model for essential services infrastructure (such as electricity, water, healthcare or education). However, PPPs involve a number of environmental, social and human rights risks. Loots points out that while international organizations, development banks and national governments have developed a number of guidelines on PPPs, the guidelines developed thus far do not consider human rights as an explicit risk or impact category, posing the risk that human rights impacts related to essential services infrastructure are overlooked. Given this context, he argues that HRIA could be a useful tool for helping to identify the human rights aspects of a PPP. It is therefore suggested that human rights analysis, including HRIA, be integrated into PPP governance frameworks for essential services infrastructure development.

\subsubsection{Part V: Current Challenges and Future Possibilities}

The contributions in Part V turn to illuminate key current challenges and future possibilities, taking a critical look at topics such as: the meaningful participation of rights-holders; the relevance of local contextual factors such as conflict; the importance of multidisciplinary teams; measuring impacts and evaluating the effectiveness of HRIA; the role of different actors, standards and frameworks in fostering accountability; and the linkages between impact assessment and the 2030 Agenda. Collectively, these insightful and critical appraisals provide valuable insights into the role that impact assessment can play in addressing the human rights impacts of business activities in a globalized context.

Beginning Part V with Chapter 17, Susan Joyce addresses the topic of rights-holder participation and capacity building in company-commissioned HRIA, noting that participation and capacity building are seen as two closely linked aspects of carrying out HRIA. While a limited number of company-commissioned assessments are currently published, practitioners from companies and consultants are accumulating experience on the challenges of carrying out such assessments with 'meaningful' participation and capacity building by rights-holders. The chapter examines these challenges from a practitioner perspective, discussing some of the limitations experienced in company-commissioned HRIAs. The chapter also considers mechanisms and strategies to increase participation and capacity of rights-holders. It is suggested that 
opportunities to improve capacity and get to meaningful participation may be greater during and after the assessment process, arguing for conceptualizing HRIA as the start of an ongoing process rather than as a static product.

In Chapter 18, Roper Cleland considers the challenges posed to companies in conflict-affected settings (CASs) and how conflict analysis can enhance HRIA. Business operations are occurring in an increasing range and number of conflict contexts and arguably, therefore, conducting HRIA in CASs requires understanding the nature and type of conflict, why this matters for human rights, and the role for more responsive analysis. The chapter considers four broad categories of contexts in which conflict-sensitive methodologies are required: (1) armed conflict; (2) armed violence; (3) post-conflict; and (4) social unrest. It explores the challenges for businesses in these conflict contexts, with particular attention to engaging stakeholders and acting upon findings. Conflicts and patterns of violence will continue to evolve, closely associated with global challenges such as climate change and humanitarian crises. Therefore, the chapter concludes with questions about what the changing nature of conflict means for business, to serve as a basis for further research and dialogue.

In Chapter 19, Rebecca DeWinter-Schmitt and Kendyl Salcito note that HRIA is inherently a multidisciplinary practice, as human rights are cross-cutting and implicate cultural, social, economic, political, legal, environmental and health topics. Yet, as the authors point out, HRIA and related fields of impact and risk assessment largely reside in silos. A growing body of literature documents the added value of merging disciplinary methods and findings in pursuit of comprehensive analysis of the impacts of business activities on people and the environment. The chapter examines such literature as pertinent to HRIA, identifying space for HRIA practitioners to integrate the methodologies, good practices and experiences across impact assessment disciplines. The literature also indicates that other fields of impact assessment would benefit from incorporating a HRBA. The chapter makes the case for transdisciplinary collaboration and concludes with a set of concrete action items for HRIA practitioners to integrate HRIA and established impact and risk assessment methodologies more fully.

In Chapter 20, Cathrine Bloch Veiberg, Gabriela Factor and Jacqueline R. Tedaldi examine the selection, design and use of indicators to measure project-level human rights impacts. Generally, literature has focused on human rights indicators from the perspective of the state. More recently, there has been a movement towards measuring and reporting initiatives that address the impact of business on human rights. However, as the authors note, these initiatives often lack the ability to measure actual outcomes at the project level. The chapter therefore considers how the application of indicators in HRIA may be useful at the project level to measure outcomes. The role of different types of indicators and how they can be used at various stages of the HRIA process is explored, as well as how lessons from other fields of impact assessment might improve the use of indicators in HRIA. The chapter concludes with a discussion on dilemmas and opportunities for improving the use of human rights indicators in impact assessment.

In Chapter 21, Deniz Utlu discusses the meaning of effectiveness in the context of HRIA and examines how it interacts with business decision-making. Derived from the UNGPs and in line with research literature on impact assessment the chapter proposes three dimensions of effectiveness: (1) the dimension of understanding of 'specific impacts on specific people'; (2) the dimension of management: addressing impacts with adequate financial resources at the appropriate level within the business; and (3) the dimension of response that leads to measurable change in a 'legitimate', 'transparent' and 'rights-compatible' way, confirmed by 
rights-holders through feedback. Given this definition, the chapter concludes that efficiency as a criterion for business decision-making may put effectiveness at risk at the level of all dimensions. However, efficiency as a concept may also be useful to evaluate if more could have been done to reach effectiveness.

Closely related to the discussion of effectiveness, in Chapter 22 I address the topic of accountability. It is argued that while accountability is referenced as a key objective of HRIA in literature and guidance, precisely how it is to be ensured is not sufficiently elaborated, discussed or problematized. Thinking critically about how accountability can be strengthened in the context of HRIA is therefore urgently necessary. To make a contribution in this regard, I examine four components of accountability that can be identified in the literature - transparency, enforceability, relationships and effectiveness - and consider how they could be better reflected in HRIA governance frameworks and practice. While accountability is more than the simple sum of these parts, I suggest that reflecting in more detail on what requirements each component poses can assist in developing a more comprehensive understanding of accountability in HRIA, including by identifying critical gaps and opportunities for optimizing enhanced accountability in practice.

In Chapter 23, Carlos Lopez discusses the role of HRIA with regard to access to remedy. HRIA is an important tool for companies and states in the context of business operations as part of due diligence. While primarily a preventative tool, impact assessments may also be relevant for the processes of establishing the legal liability of companies for alleged abuses of human rights and in the processes available to victims to search for remedy and reparation. It is discussed that there is not one but several ways in which impact assessments relate to the right to an effective remedy. For example, impact assessments could be part of the test of fault or negligence, used as a positive defence by businesses or be considered as a factor in the sentencing stage. The performance by companies or states of impact assessments, whether required under the law or not, could be a right in itself and may also be subject to certain rules, the inobservance of which may raise the prospect of a legal challenge.

Chapter 24, by Siobhán McInerney-Lankford, appraises calls for HRDD in the context of IFIs. It examines the assumption that implicit human rights coverage in environmental and social due diligence (ESDD) can be equated with a full and comprehensive consideration of human rights risk and impacts. Most IFIs have resisted calls for HRDD implementation, pointing to their suite of environmental and social policies, performance tools, instruments, frameworks and plans. The chapter explores the reasons for this traditional IFI position, as well as the nature and extent of the perceived gaps and inadequacies from a human rights perspective. McInerney-Lankford contrasts ESDD and HRDD, identifying the key qualitative differences between traditional environmental and social policies and their accompanying due diligence instruments, compared with HRDD and the tools and frameworks that emanate directly from human rights law, such as HRIA.

In Chapter 25, James Harrison questions the purpose and utility of HRIA. The chapter focuses on the adoption of HRIA as a policy instrument utilized by governments and businesses in relation to: (1) international trade agreements; and (2) business projects and activities. It is argued that the underlying objectives of HRIAs in these fields should be to increase knowledge about relevant human rights issues and accountability for international human rights obligations. However, empirical investigation conducted by Harrison into the practice of HRIAs reveals fundamental problems that make achievement of those objectives unlikely. The chapter therefore considers actions to improve the chances that HRIAs achieve their 
underlying objectives. Such actions include initiatives that introduce mandatory requirements in relation to the HRIA process (e.g., that HRIAs must be published). They also include greater focus from academic and policy communities on: (1) what is feasible through any HRIA process; and (2) overcoming issues of (perceived) partiality of assessors.

In the final contribution to Part V, Chapter 26, Birgitte Feiring discusses the potential linkages between HRIA and the 2030 Agenda, by drawing on lessons from impact assessment in an indigenous peoples' rights context in the energy sector in Latin America. The UNGPs reflect the expectation that companies avoid infringing on human rights and the 2030 Agenda calls upon all businesses to apply their creativity and innovation to solving sustainable development challenges. In combination, they constitute a unique and universal framework for coherence and a strong basis for multi-stakeholder dialogue and consensus around shared development aspirations and outcomes. Operationally, HRIAs need to embrace this combined framework by addressing the full range of human rights, along with the environmental, social and economic dimensions of sustainable development. Furthermore, Feiring argues that development actors must strive to ensure coherence between broad development strategies and policies and align individual projects with this framework. While this may appear costly or overly complex, experience suggests that it may be needed to minimize legal, financial and reputational risks, and ensure legitimacy and sustainability of positive development outcomes.

\subsubsection{Part VI: Conclusion}

The conclusion reflects on the state-of-the-art of HRIA and possible ways forward for the practice and related scholarly research. While the contributions in the Handbook are diverse in terms of the HRIA approaches featured, geographical regions, industry sectors, rights-holder focus, institutional focus, background of the authors and so on, several recurring themes can be detected across the volume. For the purposes of discussion, these are grouped and elaborated in the conclusion as follows:

- ensuring that rights-holders are at the centre of the process through meaningful participation and disaggregation;

- acknowledging and distinguishing between 'technical' and 'political' dimensions;

- making and utilizing the linkages between the project-level and wider BHR governance spheres;

- recognizing and responding to industry and country context;

- taking a multidisciplinary approach and considering the pros and cons of integration;

- maximizing and consolidating opportunities for learning, capacity building and dialogue;

- enhancing transparency and accountability through governance frameworks and actors;

- improving tools and opportunities for measurement;

- taking implementation seriously and evaluating effectiveness; and

- acknowledging limitations and recognizing value added.

\section{NOTES}

1. I would like to thank the Danish Institute for Human Rights for supporting my time to work on this chapter. I would also like to thank my colleagues Signe Andreasen Lysgaard and Kayla Winarsky 
Green, as well as the Handbook Series Editor Frank Vanclay, for their helpful comments on earlier drafts.

2. 'The process of identifying, predicting, evaluating and mitigating the biophysical, social and other relevant effects of development proposals prior to major decisions being taken and commitments made' (International Association for Impact Assessment, 1999, n.p.; see also Morgan, 2012).

3. 'Social impact assessment includes the processes of analysis, monitoring and managing the intended and unintended social consequences, both positive and negative, of planned interventions (policies, programs, plans, projects) and any social change processes invoked by those interventions. Its primary purpose is to bring about a more sustainable and equitable biophysical and human environment' (Vanclay, 2003, pp. 5-6; see also Esteves et al., 2012; Vanclay et al., 2015).

\section{REFERENCES}

Abrahams, D., \& Wyss, Y. (2010). Guide to human rights impact assessment and management (HRIAM). Washington, DC: The International Business Leaders Forum, International Finance Corporation, \& UN Global Compact.

Arla (2015). Human rights assessment in Nigeria. Viby, Denmark: Author.

Bakker, S., van den Berg, M., Düzenli, D., \& Radstaake, M. (2009). Human rights impact assessment in practice: The case of the health rights of women assessment instrument (HeRWAI). Journal of Human Rights Practice, 1(3), 436-458.

Bansal, T., \& Wyss, Y. (2013). Talking the human rights walk: Nestlé's experience assessing human rights impacts in its business activities. Copenhagen: Danish Institute for Human Rights, \& Nestlé.

Boele, R., \& Crispin, C. (2013). What direction for human rights impact assessments? Impact Assessment and Project Appraisal, 31(2), 128-134.

Braunschweig, T., Meienberg, F., Pionetti, C., \& Shashikat, S. (2014). Owning seeds, accessing food: A human rights impact assessment of UPPOV 1991 based on case studies in Kenya, Peru and the Philippines. Zurich: Berne Declaration.

BSR (2016). Human rights impact assessments and responsible divestment plan for business region Eurasia: Summary project report for Telia Company. San Francisco, CA: Author.

Buergi Bonanomi, E. (2017). Measuring human rights impacts of trade agreements - Ideas for improving the methodology: Comparing the European Union's sustainability impact assessment practice and methodology with human rights impact assessment methodology. Journal of Human Rights Practice, 9, 481-503.

Columbia Center on Sustainable Investment, Danish Institute for Human Rights, \& SciencesPo Law School (2017). A collaborative approach to human rights impact assessment. New York, NY: Authors.

Cornwall, A., \& Nyamu-Musembi, C. (2004). Putting the 'rights-based approach' to development into perspective. Third World Quarterly, 25(8), 1415-1437.

Crenshaw, K. (1991). Mapping the margins: Intersectionality, identity politics, and violence against women of color. Stanford Law Review, 43(6), 1241-1299.

Danish Institute for Human Rights, \& IPIECA (2013). Integrating human rights into environmental, social and health impact assessments: A practical guide for the oil and gas industry. Copenhagen: Authors.

de Beco, G. (2009). Human rights impact assessments. Netherlands Quarterly of Human Rights, 27(2), 139-166.

Esteves, A. M., Franks, D., \& Vanclay, F. (2012). Social impact assessment: The state of the art. Impact Assessment and Project Appraisal, 30(1), 34-42.

European Commission (2015). Guidelines on the analysis of human rights impacts in impact assessments for trade-related policy initiatives. Brussels: Author.

European Commission (2016). Handbook for trade sustainability impact assessment (2nd ed.). Brussels: European Union. 
Felner, E. (2013). Human rights impact assessments: A review of the literature, differences with other forms of assessments and relevance for development. Washington, DC: Nordic Trust Fund, \& World Bank.

FIDH, Project for Accompaniment and Solidarity International, \& Colectivo de Abogados (2016). Colombia. The human cost of oil: A human rights impact assessment on activities of Pacific Exploration \& Production Corp. in Puerto Gaitan. Executive summary. Paris: Authors.

Fundingsland Tetlow, M., \& Hanusch, M. (2012). Strategic environmental assessment: The state of the art. Impact Assessment and Project Appraisal, 30(1), 15-24.

González, A. (2014). Evaluating the human rights impact of investment projects: Background, best practices, and opportunities. Mexico City: PODER.

Götzmann, N. (2017). Human rights impact assessment of business activities: Key criteria for establishing a meaningful practice. Business and Human Rights Journal, 2(1), 87-108.

Götzmann, N., \& Bainton, N. (2019). Papua LNG human rights impact assessment: Focus on gender, security and conflict. Copenhagen: Danish Institute for Human Rights.

Götzmann, N., Vanclay, F., \& Seier, F. (2016a). Social and human rights impact assessments: What can they learn from each other? Impact Assessment and Project Appraisal, 34(1), 14-23.

Götzmann, N., Bansal, T., Wrzoncki, E., Poulsen-Hansen, C., Tedaldi, J., \& Høvsgaard, R. (2016b). Human rights impact assessment: Guidance and toolbox. Road-testing version. Copenhagen: Danish Institute for Human Rights.

Hamm, B., \& Scheper, C. (2012). Human rights impact assessments for implementing corporate responsibility: Conceptual challenges and practical approaches (Institute for Development and Peace [INEF] Research Paper Series on Human Rights, Corporate Responsibility and Sustainable Development 10/2012, University of Duisburg-Essen).

Hamm, B., Schax, A., \& Scheper, C. (2013). Human rights impact assessment of the Tampakan copper-gold project. Aachen, Germany: MISEREOR, \& Fastenopfer.

Harrison, J. (2010). Measuring human rights: Reflections on the practice of human rights impact assessment and lessons for the future (University of Warwick School of Law Legal Studies Research Paper 26/2010).

Harrison, J. (2011). Human rights measurement: Reflections on the current practice and future potential of human rights impact assessment. Journal of Human Rights Practice, 3(2), 162-187.

Harrison, J. (2013). Establishing a meaningful human rights due diligence process for corporations: Learning from experience of human rights impact assessment. Impact Assessment and Project Appraisal, 31(2), 107-117.

Harrison, J., \& Goller, A. (2008). Trade and human rights: What does 'impact assessment' have to offer? Human Rights Law Review, 8(4), 587-615.

Harrison, J., \& Stephenson, M. A. (2010). Human rights impact assessment: Review of practice and guidance for future assessments. Edinburgh: Scottish Human Rights Commission.

Hill, C., \& Newell, K. (2009). Women, communities and mining: The gender impacts of mining and the role of gender impact assessment. Melbourne, VIC: Oxfam Australia.

Hoffmann, D., Bansal, T., \& Naidu, J. (2018). Labour rights assessment: Nestlé's palm oil supply chain in Indonesia. Copenhagen: Danish Institute for Human Rights, \& The Forest Trust.

Hunt, P., \& MacNaughton, G. (2006). Impact assessments, poverty and human rights: A case study using the right to the highest attainable standard of health (World Health Organization Health and Human Rights Working Paper Series No. 6).

International Association for Impact Assessment (1999). Principles of environmental impact assessment best practice. Fargo, ND: Author.

International Human Rights Network [IHRN], Action Aid International, Amnesty EU Office, \& Terre des Hommes International Federation (2008). Human rights-based approaches and European Union development aid policies. Brussels: Author.

Kemp, D., \& Vanclay, F. (2013). Human rights and impact assessment: Clarifying the connections in practice. Impact Assessment and Project Appraisal, 31(2), 86-96.

Kuoni Travel Holding (2014). Assessing human rights impacts: India project report. Zurich: Author.

Kuoni Travel Holding, twentyfifty, \& Tourism Concern (2012). Assessing human rights impacts: Kenya pilot project. Zurich: Authors. 
Lenzen, O., \& d'Engelbronner, M. (2009). Guide to corporate human rights impact assessment tools. Utrecht, the Netherlands: Aim for Human Rights.

LKL International Consulting (2014). Human rights impact assessment of the Bisha mine in Eritrea. Montreal, QC: Author.

MacNaughton, G. (2015). Human rights impact assessment: A method for healthy policymaking. Health and Human Rights, 17(1), 63-75.

MacNaughton, G., \& Hunt, P. (2011). A human rights-based approach to social impact assessment. In F. Vanclay \& A. M. Esteves (Eds.), New directions in social impact assessment (pp. 355-368). Cheltenham, UK and Northampton, MA, USA: Edward Elgar Publishing.

Massarani, T. F., Drakos, M. T., \& Pajkowska, J. (2007). Extracting corporate responsibility: Towards a human rights impact assessment. Cornell International Law Journal, 40(1), 136-169.

Morgan, R. K. (2012). Environmental impact assessment: The state of the art. Impact Assessment and Project Appraisal, 30(1), 5-14.

Mungoven, R. (2016). Walking the talk: Exploring methodologies and applications for human rights impact assessment by the United Nations (Sabbatical report, Office of the United Nations High Commissioner for Human Rights).

Myanmar Centre for Responsible Business, Institute for Human Rights and Business, \& Danish Institute for Human Rights (2014). Myanmar oil \& gas sector wide impact assessment. Yangon, Myanmar: Authors.

Myanmar Centre for Responsible Business, Institute for Human Rights and Business, \& Danish Institute for Human Rights (2015a). Myanmar tourism sector wide impact assessment. Yangon, Myanmar: Authors.

Myanmar Centre for Responsible Business, Institute for Human Rights and Business, \& Danish Institute for Human Rights (2015b). Myanmar ICT sector-wide impact assessment. Yangon, Myanmar: Authors.

Myanmar Centre for Responsible Business, Institute for Human Rights and Business, \& Danish Institute for Human Rights (2018). Sector-wide impact assessment of limestone, gold and tin mining in Myanmar. Yangon, Myanmar: Authors.

Natour, F., \& Davis Pluess, J. (2013). Conducting an effective human rights impact assessment: Guidelines, steps and examples. New York, NY: BSR.

Norwegian Agency for Development Cooperation [NORAD] (2001). Handbook in human rights assessment: State obligations, awareness and empowerment. Oslo: Author.

Nyamu-Musembi, C., \& Cornwall, A. (2004). What is the 'rights-based approach' all about? Perspectives from international development agencies (Institute of Development Studies Working Paper No. 234).

Office of the United Nations High Commissioner for Human Rights [OHCHR] (2006). Frequently asked questions on a human rights-based approach to development cooperation (HR/PUB/06/8).

Office of the United Nations High Commissioner for Human Rights [OHCHR] (2012). The corporate responsibility to respect human rights: An interpretive guide (HR/PUB/12/02).

On Common Ground Consultants (2010). Human rights assessment of Goldcorp's Marlin mine. Vancouver, BC: Author.

Oxfam America, \& Rights \& Democracy [R\&D] (2010). Community-based human rights impact assessments: Practical lessons report from an international meeting. Montreal, QC: Authors.

Rights \& Democracy [R\&D] (2007). Human rights impact assessments for foreign investment projects: Learning from community experiences in the Philippines, Tibet, the Democratic Republic of Congo, Argentina, and Peru. Montreal, QC: Author.

Rights \& Democracy [R\&D] (2011). Getting it right: Human rights impact assessment guide. Montreal, QC: Author.

Salcito, K. (2015). Rights incorporated: Integrating human rights impact assessment into global business practices (Doctoral dissertation, Basel University).

Salcito, K., \& Wielga, M. (2012). Human rights impact assessment: A toolkit for practitioners conducting corporate HRIAs. Denver, CO: NomoGaia.

Salcito, K., Utzinger, J., Weiss, M. G., Münch, A. K., Singer, B. H., Krieger, G. R., \& Wielga, M. (2013). Assessing human rights impacts in corporate development projects. Environmental Impact Assessment Review, 42, 39-50. 
Tamir, I., \& Kearney, D. (2015). Community voice in human rights impact assessments. Washington, DC: Oxfam America.

Triponel Consulting (2017). Assessing human rights impacts at EPO's Liberia operations: Executive summary. New York, NY: Author.

United Nations Committee on Economic, Social and Cultural Rights [ICESCR Committee] (2016, March 23). Concluding observations to Canada (E/C.12/CAN/CO/6).

United Nations Committee on Economic, Social and Cultural Rights [ICESCR Committee] (2017, August 10). General comment no. 24 on state obligations under the international covenant on economic, social and cultural rights in the context of business activities (E/C.12/GC/24).

United Nations Economic Commission for Africa, \& Friedrich Ebert Stiftung (2017). The continental free trade area in Africa (CFTA) - A human rights perspective. Report. Geneva: Authors.

United Nations General Assembly (2015, October 21). Transforming our world: The 2030 agenda for sustainable development (A/RES/70/1).

United Nations Human Rights Council [UNHRC] (2007, February 5). Report of the Special Representative of the Secretary-General on the issue of human rights and transnational corporations and other business enterprises, John Ruggie. Human rights impact assessments - resolving key methodological questions (A/HRC/4/74).

United Nations Human Rights Council [UNHRC] (2008, April 7). Protect, respect and remedy: A framework for business and human rights. Report of the Special Representative of the Secretary-General on the issue of human rights and transnational corporations and other business enterprises, John Ruggie $(\mathrm{A} / \mathrm{HRC} / 8 / 5)$.

United Nations Human Rights Council [UNHRC] (2011a, March 21). Report of the Special Representative of the Secretary-General on the issue of human rights and transnational corporations and other business enterprises, John Ruggie. Guiding principles on business and human rights: Implementing the United Nations 'protect, respect and remedy' framework (A/HRC/17/31).

United Nations Human Rights Council [UNHRC] (2011b, December 19). Report of the Special Rapporteur on the right to food, Olivier De Schutter. Addendum: Guiding principles on human rights impact assessments of trade and investment agreements (A/HRC/19/59/Add.5).

Vanclay, F. (2003). International principles for social impact assessment. Impact Assessment and Project Appraisal, 21(1), 5-12.

Vanclay, F. (2014). Developments in social impact assessment: An introduction to a collection of seminal research papers. In F. Vanclay (Ed.), Developments in social impact assessment (pp. xvxxxix). Cheltenham, UK and Northampton, MA, USA: Edward Elgar Publishing.

Vanclay, F., \& Esteves, A. M. (2011). Current issues and trends in social impact assessment. In F. Vanclay \& A. M. Esteves (Eds.), New directions in social impact assessment: Conceptual and methodological advances (pp. 3-19). Cheltenham, UK and Northampton, MA, USA: Edward Elgar Publishing.

Vanclay, F., Esteves, A. M., Aucamp, I., \& Franks, D. M. (2015). Social impact assessment: Guidance for assessing and managing the social impacts of projects. Fargo, ND: International Association for Impact Assessment.

Vattenfall (2017). A human rights risk assessment in Colombia: Vattenfall's efforts on coal supply chain responsibility. Solna, Sweden: Author.

Wachenfeld, M., Schuele, W., \& Kimotho, R. (2017). Human rights impact assessment. A report about the East African coffee sector in: Kenya, Uganda, the Democratic Republic of the Congo, Rwanda, Ethiopia and Burundi. London: Institute for Human Rights and Business, Coop Danmark, \& African Coffee Roasters.

Walker, S. (2009). The future of human rights impact assessments of trade agreements. Antwerp, Belgium: Intersentia.

Walker, S. (2011). The United States-Dominican Republic-Central American free trade agreement and access to medicines in Costa Rica: A human rights impact assessment. Journal of Human Rights Practice, 3(2), 188-213.

Watson, G., Tamir, I., \& Kemp, B. (2013). Human rights impact assessment in practice: Oxfam's application of a community-based approach. Impact Assessment and Project Appraisal, 31(2), 118-127.

Wielga, M., Salcito, K., Krieger, G. and Wise, E. (2009). Human rights impact assessment on the proposed Nuiguyo gold mine in Indonesia, owned by Aimec Minerals. Denver, CO: NomoGaia. 